\title{
Does the PPP condition hold for oil-exporting countries? A quantile cointegration regression approach
}

\author{
Matthew Lyon * Jose Olmo ${ }^{\dagger}$
}

\begin{abstract}
This paper examines the legitimacy of the Purchasing Power Parity condition applied to the quantile process for twelve oil-exporting countries: Algeria, Angola, Canada, Colombia, Indonesia, Iran, Kazakhstan, Kuwait, Mexico, Nigeria, Norway, and Russia. The application of quantile unit root inference methods to test the specification of the PPP condition in the quantile process yields limited support to the equilibrium condition. However, the application of quantile cointegration methods that estimate the equilibrium relationship between national prices and the nominal exchange rate is much more supportive of a generalized PPP condition that varies across countries and quantiles. Our empirical findings suggest that the distribution of the nominal exchange rate reflects a nonlinear equilibrium relationship between national prices that varies widely between the central and tail quantiles and is country-specific.
\end{abstract}

JEL Classification: C22, F31, G1

Keywords: Oil-exporting countries, Purchasing power parity, Quantile cointegration, Quantile unit root test

*Department of Economics. University of Southampton.

${ }^{\dagger}$ Corresponding Author: Department of Economics, University of Southampton, Highfield Lane, Southampton, SO17 1BH. United Kingdom. E-mail: J.B.Olmo@soton.ac.uk 


\section{Introduction}

The PPP theory states that in the long-run the exchange rate between two countries is determined by their relative price levels. For the majority of oil-exporting countries, oil makes up a large proportion of their merchandise exports, whilst in some cases countries become specialised to the point of only exporting one commodity, oil. For example, fuel exports account for over $90 \%$ of all exports for four of the countries analysed in our study. ${ }^{1}$ As a consequence, oil is the main determinant of the economic conditions in these countries; especially the price level and the exchange rate.

In countries with economic activities so heavily linked to oil, fluctuations in oil prices impact the exchange rate through many different channels. For example, changes in inflation potentially lead to systematic deviations from PPP in the long-run, if countermeasures are not implemented. This link has been well established in the literature, see inter alios, Amano and Van Norden (1998) and Coudert, Mignon, et al. (2008). The main channel through which the price of oil may influence the exchange rate of an oil-exporting country being the terms of trade channel. Backus and Crucini (2000) show that most of the variation in terms of trade can be attributed to the variation in oil prices. These impacts are exacerbated by the unique volatility historically exhibited by oil prices. Dehn (2000) finds oil to be twice as volatile as other traded commodities. Moreover, Agenor, McDermott, et al. (2000) finds this volatility impacts oil exporting countries more than oil importing countries. Finally, Mendoza (1995) highlights that trade shocks have more impact in countries that only export a few commodities, such as oil-exporting countries.

As a result, oil-exporting countries exhibit a number of economic characteristics that may invalidate PPP. Firstly, large nominal exchange rate volatility is likely to lead to deviations from PPP. This is empirically supported by Alba and Papell (2007). Secondly, limited openness to trade, whilst oil-exporting countries rely on exporting their oil, a number of them still restrict trade of other goods. For example, Algeria, and Iran have extremely high import tariffs relatively to the average. Alba and Park (2003) show that PPP is more likely to hold in countries open to trade. Finally, low GDP growth is experienced by 7 of the 12 countries in this study. Whilst the Balassa-Samuelson effect suggests PPP is more likely to hold in high productivity growth countries relative to

\footnotetext{
${ }^{1}$ Angola, Algeria, Kuwait, and Nigeria. Please see World Bank (2016) for the full list.
} 
low productivity growth countries the empirical evidence has been mixed. Cheung and Lai (2000) finds that this is not the case.

An important limitation of the majority of these empirical studies is that the PPP hypothesis is assessed using standard unit root type tests. In particular, the literature explores the existence of cointegration between the time series of price indices of different countries, see MacDonald and Murphy (1989) and Taylor (1988) that, under the null hypothesis that the PPP condition holds, is reflected in the stationarity of the real exchange rate. These tests are, however, silent about the stationarity of the different conditional quantiles of the distribution of the real exchange rate. This analysis may be much more relevant under the assumption that the distribution of the real exchange rate is asymmetric and leptokurtic.

The existence of asymmetries in the distribution of the real exchange rate is widely acknowledged in the empirical literature. Taylor, Peel, et al. (2001) show that the speed of adjustment of the real exchange rate should vary depending on the level of disequilibrium. This literature predicts that the speed of adjustment is fastest when the shocks are largest implying that size matters. This means that PPP is more likely to hold in the extreme quantiles of the distribution as a result of policy responses. In a similar vein, Nikolaou (2008) also reports that the larger the deviations from equilibrium, the faster the speed of adjustment to the equilibrium should be. This author concludes that, tests that only focus on the average of the real exchange rate are inappropriate and suffer from an upward bias. The speed of adjustment might also differ not only for different magnitudes of deviations from the equilibrium, but for the sign of the disequilibrium, entailing that positive and negative deviations have different impacts on the PPP condition. Dutta and Leon (2002) argue that asymmetries in policy response to changes in the exchange rate can lead to asymmetric returns to equilibrium.

Quantile regression provides a more robust approach for testing the PPP condition because it allows for a differing speed of adjustment by focusing on the whole distribution of the real exchange rate and not just the mean. To date only Chang and Liu (2010) have attempted to account for these asymmetries in oil-exporting countries using threshold cointegration tests. These methods accommodate the existence of a piecewise linear relationship between prices and the exchange rate that differs across regimes. With these empirical features in mind, the current paper examines the legitimacy of the PPP hypothesis for twelve oil-exporting countries: Algeria, Angola, Canada, Colombia, 
Indonesia, Iran, Kazakhstan, Kuwait, Mexico, Nigeria, Norway, and Russia. The choice of this set of countries is to capture the whole spectrum of oil-exporting economies. We study each country separately as our aim is to focus on the quantile process of the real exchange rate of each national currency against the US dollar. This is done using monthly data from January 1996 - Dec 2016.

Our main contribution is to study the PPP condition applying quantile regression methods. We do this in two stages. First, we perform quantile unit root inference to establish the validity of the PPP theory for the quantile process. In particular, we apply the extension of the Dickey-Fuller test proposed in Koenker and Xiao (2004, 2006) to the quantile process of the bilateral real exchange rate for each of the countries in our sample. The hypothesis of interest is whether the quantile process is stationary or not. The stationarity of the quantiles of the distribution of the real exchange rate entails an equilibrium relationship between prices. In this scenario there is no need to estimate the relationship between prices and the nominal exchange rate as this is given by the definition of the real exchange rate. The empirical results obtained in this context for our set of countries find limited support for PPP. Support for the PPP condition is only found in the lower quantiles for the countries of Angola, Indonesia, Kazakhstan, and Mexico; and in the central quantile in the case of Russia. Thus, the PPP condition is not supported across the whole distribution of the remaining seven oil exporting countries of Algeria, Canada, Colombia, Iran, Kuwait, Nigeria, and Norway.

Second, we extend the PPP hypothesis in distribution by estimating the cointegration relationship between the national price indices and the nominal exchange rate for different quantiles of the conditional distribution. In order to validate if the estimated relationships obtained from the quantile cointegration analysis really support an equilibrium relationship, we test for the stationarity of the corresponding residual series. These residual series are no longer interpreted as the real exchange rate and vary across quantiles. The empirical results obtained in this scenario are more supportive of a longrun equilibrium condition for the quantile process and suggest that there indeed exists a nonlinear cointegration relationship between national prices for oil-exporting countries. In particular, we find support for the existence of quantile cointegration between the exchange rate and price levels in ten of the twelve oil-exporting countries. These results are robust to the choice of quantile, however, the specific form of the relationship between national prices and the corresponding exchange rate, driven by the cointegration 
parameter estimates, varies across quantiles and is country-specific.

To the best of our knowledge, this is the first paper to apply quantile autoregression inference to assess the PPP condition in distribution as well as a comprehensive application of the PPP condition to oil-exporting countries. The majority of previous papers focused on oil-exporting economies, such as Chang, Lu, Liu, et al. (2010), BahmaniOskooee, Chang, Cheng, et al. (2015) and Mehrara (2007), use panel data cointegration methods but do not carry out the analysis of the PPP condition for different quantiles of the distribution. Furthermore, Chang, Lu, Liu, et al. (2010) and Bahmani-Oskooee, Chang, Cheng, et al. (2015) only analyse a small set of countries, whilst Mehrara (2007) has limited observations due to the availability of yearly data for their study.

The remainder of the paper is organised as follows. Section 2 provides an overview of PPP, a summary of the relevant literature, as well as the rationale for the quantile methodology. Section 3 presents a technical summary of the quantile methodology, as well as a discussion of the extension of the quantile method to estimate the long-run equilibrium relationship for the quantile process. Section 4 details the data used in this study, presents the empirical results for our set of countrie and discusses the implications of our empirical findings. Finally, Section 5 concludes this study. Tables and figures are collected in an appendix.

\section{Literature Review}

There are only a handful of papers that have specifically focused on PPP in oil-exporting countries. Whilst there has been some support, the literature is not conclusive. There has been little to no attempt to find support for PPP in oil-exporting countries using time series data, with almost all the literature resorting to panel unit root tests. The first, Mehrara (2007), uses both panel unit root tests and panel cointegration tests on the black market exchange rate. Bahmani-Oskooee, Miteza, et al. (2002) argue that the black market exchange rate is more appropriate when testing PPP in a developing country because it better represents market forces. Despite this, Mehrara (2007) strongly rejects the PPP hypothesis for 13 oil-exporting countries, seven of which are the focus of this study ${ }^{2}$. Other studies present a limited sample of oil-exporting countries in their panel approach, omitting some of the most oil dependent countries such as Angola,

\footnotetext{
${ }^{2}$ Algeria, Colombia, Indonesia, Iran, Kuwait, Mexico, and Nigeria.
} 
Kuwait, and Nigeria in the case of Bahmani-Oskooee, Chang, Cheng, et al. (2015), and Angola, and Kazakhstan in the case of Chang, Lu, Liu, et al. (2010). Chang, Lu, Liu, et al. (2010) employ four different panel unit root tests only finding support for PPP when applying panel SURADF tests ${ }^{3}$; support for PPP is only found in a little over half of the countries studied. These authors reject PPP in the countries of Kuwait, Nigeria, and Saudi Arabia. Bahmani-Oskooee, Chang, Cheng, et al. (2015) findings are more conclusive, providing support for PPP in five of the six oil-exporting countries analysed. However, none of these papers account for the asymmetries in shocks to the exchange rate at different quantiles. As previously stated the only paper that has account for these asymmetries is Chang and Liu (2010). They conclude there is evidence of a long-run relationship supporting PPP, and that the adjustment mechanism back to equilibrium after a shock is asymmetric. The current paper aims to provide more detail on the precise nature of this process.

The quantile methodology, based on the quantile autoregressive model (QAR) and quantile unit roots by Koenker and Xiao (2004, 2006), has been recently employed in the context of PPP successfully by Nikolaou (2008), Bahmani-Oskooee and Ranjbar (2016), and Bahmani-Oskooee, Chang, Chen, et al. (2017). As noted by Hosseinkouchack and Wolters (2013), there are a number of advantages to this approach. Most relevantly it allows both positive and negative shocks of different magnitudes to have a different impact on the real exchange rate. These authors state that the quantile unit root tests have higher power than traditional unit root tests, as well as perform better in the case of departure from Gaussian residuals. The first to employ this approach was Nikolaou (2008). Using bilateral exchanges rates against the US dollar (USD) for the UK, Japan, and Euro area, this author finds some support of PPP. Bahmani-Oskooee and Ranjbar (2016) find support in 16 of 23 OECD countries; having previously only found support in six countries using traditional unit root tests. Focusing on less developed, transition countries, Bahmani-Oskooee, Chang, Chen, et al. (2017) found support of PPP for all seven countries; having previously only found support in one country. As yet however, this methodology has not been extended to oil-exporting countries. This paper aims to fill this void in the literature.

\footnotetext{
${ }^{3}$ Seemingly Unrelated Regressions Augmented Dickey-Fuller tests.
} 


\section{Econometric methods}

This section presents the econometric methodology to test for the presence of an equilibrium PPP condition for the quantile process. Before this, we briefly review the PPP condition. Let $P_{t}$ be the dollar price of an unchanging basket of goods purchased in the U.S. Similarly, let $P_{f, t}$ be the price of an unchanging basket of goods purchased in a foreign country, and $e_{t}$ the nominal exchange rate defined as the relative price of the two currencies. The PPP condition is satisfied if

$$
e_{t}=\frac{P_{t}}{P_{f t}}
$$

This condition is hardly satisfied as it implies that $\ln P_{t}-\ln P_{f, t}-\ln e_{t}=0$. In practice, the PPP condition is tested, instead, by assessing the stationarity of this process. More

formally, let $r e_{t}=\frac{e_{t} P_{f t}}{P_{t}}$ define the real exchange rate. This quantity measures the relative price of two baskets of goods in different countries compared to the nominal exchange rate $e_{t}$ that measures the relative price of the two currencies. In this framework, the PPP condition is satisfied if the natural logarithm of the real exchange rate, denoted as $\operatorname{lre}_{t}$ hereafter, is stationary.

It is almost always the case that exchanges rates and price levels are integrated of order 1. The stationarity of $l r e_{t}$ entails that prices and the exchange rate move together in the long-run. If this is not the case, and PPP does not hold, lre $_{t}$ is a unit root process, where the variables have a tendency to drift apart. As discussed in the previous section, oil-exporting countries share features that make difficult for the PPP condition to hold. However, the presence of asymmetries in the distribution of the real exchange rate is an stylized fact, see Chang, Lu, Tang, et al. (2011), Sarno (2000), and Serletis and Gogas (2000), in many of these countries. This empirical feature suggests that the PPP condition can be satisfied for some quantiles of the conditional distribution of prices and the exchange rate but not for others. The next section discusses the extension of unit root tests to the quantile process proposed in Koenker and Xiao (2004).

\subsection{QAR Estimation and Inference}

Let $l r e_{t}$ denote the natural log of real exchange rate and $\epsilon_{t}$ a serially uncorrelated zeromean error term. The testing equation for the augmented Dickey-Fuller test is

$$
l r e_{t}=a+\alpha l r e_{t-1}+\sum_{i=1}^{q-1} \phi_{i} \Delta l r e_{t-i}+\epsilon_{t}
$$


with $q$ the number of lags of the first differences $(\Delta)$ of $l r e_{t}$ and $\alpha$ the parameter of interest. If $\alpha=1$, then the real exchange rate is said to have a unit root and shocks have a permanent impact on the real exchange rate. In this case the exchange rate deviations never return to their long-run equilibrium and the PPP hypothesis is not supported. Conversely, if $\alpha<1$, then the real exchange rate is stationary, and mean reverting.

Traditional unit root tests however, only focus on the conditional mean. To analyse the persistence in more detail, this paper looks at the whole conditional distribution of $l r e_{t}$, estimating the above equations using quantile autoregression methods developed by Koenker and Xiao (2004). The $\tau$ th conditional quantile is defined as the value $Q_{\tau}\left(\operatorname{lre}_{t} \mid l r e_{t-1}, \ldots, \operatorname{lr} e_{t-q}\right)$ such that the probability that the exchange rate conditional on its recent history will be less than the conditional quantile is $\tau$. Following Koenker and Xiao (2004), the extension of the Dickey-Fuller test to the quantile process can be implemented by using the testing equation

$$
Q_{\tau}\left(\operatorname{lre}_{t} \mid \operatorname{lr} e_{t-1}, \ldots, \operatorname{lr}_{t-q}\right)=a(\tau)+\alpha(\tau) \operatorname{lr} e_{t-1}+\sum_{i=1}^{q-1} \phi_{i}(\tau) \Delta l r e_{t-i} .
$$

Estimating the above equation at different quantiles $\tau \in\{n / 10: n=1, \ldots, 9\}$ returns a set of estimates of the persistence parameter $\alpha(\tau)$. The null hypothesis for each quantile is equivalent to the traditional unit root tests. The null hypothesis $H_{0, \tau}$ is $\alpha(\tau)=1$. Testing the null hypothesis at different values of $\tau$ provides a more detailed analysis of shocks on the real exchange rate, one that allows for different signs and magnitudes. For the full technical details of this test please refer to Koenker and Xiao (2004). A brief explanation will be outlined here. Let $\left(\widehat{\alpha}(\tau), \widehat{a}(\tau), \widehat{\phi}_{1}(\tau), \ldots, \widehat{\phi}_{q}(\tau)\right)$ be the quantile estimator vector of $\left(\alpha(\tau), a(\tau), \phi_{1}(\tau), \ldots, \phi_{q}(\tau)\right)$. This estimator is the solution to the minimization problem:

$$
\min _{\left(\alpha(\tau), a(\tau), \phi_{1}(\tau), \ldots, \phi_{q}(\tau)\right)} \sum_{t=1}^{T} \rho_{\tau}\left(\operatorname{lr} e_{t}-a(\tau)-\alpha(\tau) \operatorname{lr} e_{t-1}-\sum_{i=1}^{q-1} \phi_{i}(\tau) \Delta l r e_{t-i}\right)
$$

where $\rho_{\tau}=x(\tau-I(x<0))$ is the usual check function and $T$ is the sample size.

To test $H_{0, \tau}: \alpha(\tau)=1$ for $\tau \in(0,1)$, the t-statistics for $\alpha(\tau)$ proposed by Koenker and Xiao (2004) are used, which can be written as

$$
t_{n}(\tau)=\frac{f\left(\widehat{F^{-1}(\tau)}\right)}{\sqrt{\tau(1-\tau)}}\left(\operatorname{ler}_{-1}^{\prime} M_{Z} l_{e r}\right)^{1 / 2}(\widehat{\alpha(\tau)}-1)
$$


where $f(u)$ and $F(u)$ are the probability and cumulative density functions of $\epsilon_{t}$, respectively, $l r e_{-1}$ is the vector of lagged log-real exchange rate, and $M_{z}$ is the projection

matrix of $l e r_{t}$ onto the space orthogonal to $Z=\left(1, \Delta l r e_{t-1}, \Delta l r e_{t-2}, \ldots, \Delta l r e_{t-q+1}\right)^{T}$ for the Koenker and Xiao (2004) approach. The results derived in Koenker and Xiao (2004) are used to calculate the unique critical values of the above t-statistic for each different quantile level. The main advantage to this test is that it has more power compared to traditional unit root tests, as shown by Koenker and Xiao (2004) in their simulations. Nikolaou (2008) and Hosseinkouchack and Wolters (2013) state the additional advantages to this approach, both in general, and in the context of the PPP hypothesis.

\subsection{Quantile cointegration and the PPP condition}

The absence of cointegration between national prices and the nominal exchange rate has been frequently discovered in applications using traditional analysis on time series. One explanation of this empirical observation is the existence of cointegrating coefficients that vary across quantiles and that characterize different long-run equilibrium relationships for each quantile of the distribution of the residual series. In this scenario, the typical PPP hypothesis can wrongly reject the null hypothesis of cointegration if the cointegrating parameters are forced to satisfy the one-to-one relationship imposed by economic theory.

In this section, we propose a more flexible PPP equilibrium condition that is obtained from estimating the cointegration relationship between national prices and the nominal exchange rate at different quantiles. We follow Xiao (2009) and model the quantile of the natural log of the nominal exchange rate as

$$
Q_{\tau}\left(l e_{t}\right)=\beta_{0}(\tau)+\beta(\tau) l P_{t}+\beta_{f}(\tau) l P_{f, t},
$$

with $l e_{t}=\ln e_{t}, l P_{t}=\ln P_{t}$ and $l P_{f, t}=\ln P_{f, t} ; \beta_{0}(\tau), \beta(\tau)$ and $\beta_{f}(\tau)$ denote the cointegration parameters of the model. For each quantile $\tau$, we estimate the cointegration parameters $\left(\beta_{0}(\tau), \beta(\tau), \beta_{f}(\tau)\right)$ by minimizing the objective function

$$
\min _{\left(\beta_{0}(\tau), \beta(\tau), \beta_{f}(\tau)\right)} \sum_{t=1}^{T} \rho_{\tau}\left(l e_{t}-\beta_{0}(\tau)-\beta(\tau) l P_{t}-\beta_{f}(\tau) l P_{f t}\right) .
$$

The residuals of this model are specific to each quantile $\tau$, and constructed as

$$
u_{t}(\tau)=l e_{t}-\widehat{\beta}_{0}(\tau)-\widehat{\beta}(\tau) l P_{t}-\widehat{\beta}_{f}(\tau) l P_{f, t}
$$


In a second stage, to assess statistically the cointegration relationship, we test the stationarity of the process $u_{t}(\tau)$ for each $\tau \in(0,1)$. This is done by applying standard unit root tests to the time series $u_{t}(\tau)$ for each $\tau \in(0,1)$.

\section{Empirical results}

Our empirical analysis covers twelve oil-exporting countries: Algeria, Angola, Canada, Colombia, Indonesia, Iran, Kazakhstan, Kuwait, Mexico, Nigeria, Norway, and Russia. This study uses monthly nominal exchange rate and consumer price index (CPI) data from January 1996 to December 2016 to construct bilateral real exchange rates. Due to data availability some oil-exporting countries had to be excluded from this study. For example, in 2003 Iraq reissued their currency, significantly reducing the time span that could be analysed.

The nominal exchanges rates with respect to the U.S. dollar and the consumer price indexes were taken from the International Financial Statistics of the International Monetary Fund (IMF). CPI data use the base year of 2010. The rationale behind using the U.S. dollar as the exchange rate partner for the oil-exporting countries is that the U.S. is one of the main trading partners for each of these twelve countries, mainly due to their demand for oil. All variables are transformed into their natural logarithm counterpart before conducting the analysis. Table 1 reports summary statistics for each country. It is clear for all countries that the distributions of the real exchange rate experience some form of asymmetry. This is formally analysed by the Jarque-Bera test of normality that rejects the null hypothesis of normality of the real exchange rate for all twelve countries at the five percent significance level. This result suggests that it might be more fruitful to consider each quantile separately rather than modeling the quantiles as the result of a location-scale transformation of the PPP condition for the mean.

\subsection{Traditional Unit Root Tests}

Here the analysis is carried out by the three conventional unit root tests on the bilateral real exchange rate as a benchmark, namely, Augmented Dickey Fuller (ADF), PhillipsPerron (PP), and Kwiatkowski-Phillips-Schmidt-Shin (KPSS). Based on the Jarque-

Bera test results, that show all of the 12 countries can not be described as having a normal distribution, the quantile unit root tests will be better suited to the asymmetric 
distribution. Previous papers using this methodology, Bahmani-Oskooee, Chang, Chen, et al. (2017), find that the quantile unit root tests reject the null hypothesis of a unit root where the traditional tests did not. It is therefore useful to make the comparison in order to justify the quantile approach. For the ADF unit root tests, the lag length is selected using the AIC criteria, and for the PP and KPSS test, the bandwidth is selected using the Bartlett Kernel. None of these tests allow for a trend in the data. The results are reported in Table 2.

Looking firstly at levels, it is clear that the ADF and PP test fail to reject the null hypothesis of a unit root at the $5 \%$ significance level. Only in the case of Indonesia do they reject the null hypothesis at any level of significance. This suggests that there is a unit root in the levels of the real exchange rate for all the countries in the sample, providing no support for the PPP hypothesis. The KPSS test supports these results, rejecting the null hypothesis of stationarity in the case of Angola, Canada, Colombia, Indonesia, Kazakhstan, Kuwait, and Russia. The KPSS test finds the same conclusion with the added exception of Kazakhstan. These results are in-line with the existing literature. Most notably, Bahmani-Oskooee, Chang, Cheng, et al. (2015) find the traditional unit root tests fail to reject the null hypothesis of a unit root for the oil-exporting countries of Algeria, Indonesia, Norway, Russia, Saudi Arabia, and Venezuela. They reason that this is due to the low power of these tests in finite samples when the real exchange rate is highly persistent. The unit root tests of the first difference of the real

exchange rate reject the null hypothesis of unit root (fail to reject the null hypothesis of stationary for the KPSS test) in all the countries at the $1 \%$ confidence level. Therefore, the first difference of the process is stationary. Again, this replicates results commonly found in the literature.

\subsection{Estimation of the quantile autoregressive process}

It is informative to first look at the estimates of $\alpha(\tau)$ for $\tau \in\{n / 10: n=1, \ldots, 9\}$. Figure $1(\mathrm{a}-\mathrm{l})$ in the appendix show the estimation of the persistent parameter, $\alpha(\tau)$, and the constant, $a(\tau)$, at each quantile as well as the $95 \%$ confidence bands indicated by the grey area. Left hand side is for the parameter estimates of $\alpha(\tau)$ and right hand side for the parameter estimates of $a(\tau)$. The horizontal dashed lines show the estimate, and 95\% confidence bands, for a standard regression for comparison purposes. The constant parameter, $a(\tau)$, is used to access the magnitude of the shocks. It is clear that 
the impact of shocks varies greatly across the distribution. The behaviour falls into one of three categories. The first is described by an upward slope, and describes countries such as Canada, and Norway. Here, the lower quantiles experience a negative shock whilst the higher quantiles experience a positive shock, with the medium intercepting zero. In this case, the shocks appear to be symmetric in their impact. Nikolaou (2008) states that these shocks can be interpreted as follows: a negative shock is interpreted as an appreciation, and a positive shock is interpreted as a depreciation of the currency. The second category is the opposite of the first, and can be seen with countries such as Indonesia and Kazakhstan. Here, the interpretation is reversed: they experience positive shocks in their lower quantile, and negative shocks in the higher quantiles. Finally, there are countries like Nigeria which appear to have experienced very little shocks over the sample period. The estimation of $a(\tau)$ is fairly uniform across the distribution, with all values close to zero.

To analyse the mean reverting behaviour of the quantile process across $\tau$, we focus on the estimations of $\alpha(\tau)$ for each quantile on the left hand side of Figure 1 (a - l). Again, the mean reverting behaviour can be grouped into three categories. The first is described by an inverted U shape, countries such as Algeria, Angola, and Canada. Here, the process is most persistent in the middle quantiles, $\tau=0.3-0.7$, whilst the persistence is greatly reduced in the extreme quantiles. The interpretation of this is as follows. Smaller shocks have no effect on the mean reverting process and it continues to be a unit root. However, extreme shocks whether positive or negative seem to be able to induce mean reversion. We would, therefore, expect to find a unit root in the middle quantiles, rejecting the PPP condition, but reject the unit root hypothesis in the extreme quantiles, providing support for PPP for those quantiles.

The second category can be described as an upward sloping curve, countries such as Indonesia, and Mexico. Here, the persistence is greatest in the upper quantiles, and weakest in the lower quantiles. The interpretation of this is that negative shocks induce mean reversion, and thus only have temporary effects, whilst positive shocks are persistent and dictate the long-run path of the process. Bahmani-Oskooee, Chang, Chen, et al. (2017) highlight the policy implications of these findings, stating that the best time to improve their trade balance would be when they have experienced a positive shock due to its persistence. In this case we would expect to find a unit root in the upper quantiles, and reject the unit root hypothesis in the lower quantiles. 
The final category has the opposite interpretation as the above, countries such as Iran, and Norway. Here it is the case that persistence is strongest in the lower quantiles, and weakest in the higher quantiles. Thus, positive shocks have a temporary effect, and do not influence the exchange rate in the long-run, but negative effects are persistent and dictate the process in the long-run. This behaviour is perhaps the most intuitive for an oil-exporting country, as depreciations would be permanent and have a favourable effect on their trade balance, see Bahmani-Oskooee, Chang, Chen, et al. (2017) for a study of Eastern European countries. In this case we would expect to find a unit root in the lower quantiles, and reject the unit root hypothesis in the upper quantiles.

\subsection{The quantile unit root hypothesis}

Tables 3, 4, and 5 report the results of the quantile unit root test of Koenker and Xiao (2004), including the t-statistic and critical values at the 5\% level. The null hypothesis is $H_{0, \tau}: \alpha(\tau)=1$ for $\tau=0.1,0.2, \ldots, 0.9$ using the test statistic outlined in equation (4).

The null hypothesis cannot be rejected across the whole distribution in the case of Algeria, Canada, Colombia, Iran, Kuwait, Nigeria, and Norway. Thus, for seven of the twelve oil-exporting countries there is no support for the PPP hypothesis. It is worth noting these results contradict those of Chang, Lu, Liu, et al. (2010), and Bahmani-Oskooee, Chang, Cheng, et al. (2015), both of which find support for the PPP hypothesis in the countries of Algeria, Iran, and additionally Norway in the case of Chang, Lu, Liu, et al. (2010). However, the null hypothesis of a unit root is rejected in the lower extreme quantiles for Angola, Indonesia, Kazakhstan, and Mexico. For these countries negative shocks are not persistent, and have no long-term impacts on the real exchange rate, as predicted above, formalising the assumption that the PPP condition can be expected to hold for low quantiles of the conditional distribution of the real exchange rate. However, the occurrence of large positive shocks implies that PPP does not hold.

On the basis of these results, in the case of oil-exporting countries we can provide very limited support for the PPP hypothesis. In general, positive shocks seem to always have a permanent effect on the exchange rate of an oil-exporting country, and only in a handful of countries is this not the case with negative shocks. Therefore, under normal conditions PPP is unrealistic, and only in the presence of extreme negative shocks may it hold. These results confirm the aforementioned policy implications outlined by 
Bahmani-Oskooee, Chang, Chen, et al. (2017).

\subsection{A generalized PPP condition using quantile cointegration}

The above empirical findings shed very limited support to the PPP hypothesis across quantiles of the distribution of the real exchange rate. An alternative is to assess the extent of this relationship if the PPP hypothesis is extended to accommodate a more flexible specification of the relationship between national prices and the nominal exchange rate. We contemplate the existence of a nonlinear multiplicative relationship between national prices and the nominal exchange rate such that, in equilibrium,

$$
e_{t}=\alpha \frac{P_{t}^{\beta}}{P_{f t}^{\beta_{f}}},
$$

with $\alpha, \beta$ and $\beta_{f}$ the parameters of the model. This relationship can be tested using OLS and quantile regression methods to obtain the corresponding weights that determine equilibrium between national prices and the exchange rate. An empirical testable version of (8) is obtained by applying logs and adding a zero-mean error term, such that

$$
l e_{t}=\beta_{0}+\beta l P_{t}+\beta_{f} l P_{f t}+u_{t},
$$

with $\beta_{0}=\ln \alpha$. The parameters of this model can be estimated using OLS methods. Alternatively, we can obtain their quantile counterparts by applying quantile regression methods to (9) as explained in Section 3.2. In this framework, the parameters of interest are $\beta(\tau)$ and $\beta_{f}(\tau)$. Thus, in the interest of space we omit discussion of the vector of parameter estimates corresponding to $\beta_{0}(\tau)$.

In order to gain some understanding of the parameter estimates across quantiles, we report in Figure $2(\mathrm{a}-1)$ the quantile processes corresponding to the parameter estimates of $\beta(\tau)$ (left hand side) and $\beta_{f}(\tau)$ (right hand side) using expression (6). For comparison purposes, the black dotted line, and grey dotted line, represent the OLS estimates and $95 \%$ confidence bands, respectively.

An informal analysis of these estimates can be carried out by comparing the magnitude of the parameter estimates $\beta(\tau)$ and $\beta_{f}(\tau)$ across quantiles. For the PPP condition to hold, the estimates should mirror each other around zero. For example, see Figure 2 (k) presenting the estimates for Norway. In the lower quantiles, the quantile estimate corresponding to the coefficient $\beta(\tau)$ is around 4 , whilst the coefficient estimate $\beta_{f}(\tau)$ 
associated to the U.S. price level is around -4 . These parameters perfectly offset each other around zero. This is an example where PPP is likely to hold, however, this statement should be formalised by also testing the stationarity of the corresponding residual series at the particular quantile $\tau$. The case of Mexico provides a counterexample. The parameter estimates corresponding to both price levels are positive through all quantiles suggesting an unconventional equilibrium condition characterised by two sets of parameters $\beta(\tau)$ and $\beta_{f}(\tau)$ with the same sign. This unconventional PPP equilibrium condition is, however, rejected as the analysis of the corresponding residuals $u_{t}(\tau)$ does not find evidence to reject the null hypothesis of unit roots across quantiles. Tables 6 and 7 report the p-values for the augmented Dickey-Fuller test without drift (top rows) and with drift (bottom rows) for each quantile as well as the OLS equivalent.

The most appropriate unit root test in this context is the augmented Dickey-Fuller test with drift. Under the flexible specification (6), our empirical findings show more support for the PPP hypothesis. In seven of the twelve countries the null hypothesis of a unit root in the quantile residuals is rejected in every quantile of the distribution. In a further three countries the null hypothesis is rejected in the upper extreme quantiles, where it previously was not. Based on these results, there is a long-run relationship between price levels and the nominal exchange rate in oil-exporting countries as PPP suggests. However, the estimations suggest the relationship is not one-to-one as stated in the PPP theory but nonlinear. The nonlinearities obtained in the relationship between prices vary across quantiles and are country-specific. Furthermore, the parameter estimates contain information about the relative importance of national prices in determining the nominal exchange rate.

\section{Conclusion}

This study analyses the purchasing power parity hypothesis for twelve oil-exporting countries: Algeria, Angola, Canada, Colombia, Indonesia, Iran, Kazakhstan, Kuwait, Mexico, Nigeria, Norway, and Russia using monthly data from January 1996 to December 2016. Traditional unit root tests fail to account for different magnitudes and asymmetries in shocks, subsequently failing to find support for the PPP hypothesis. As such this paper applies quantile unit root tests proposed by Koenker and Xiao (2004) that allow for different shocks at different quantiles. To the best of our knowledge, this 
is the first paper to apply these unit root tests to such countries. Despite the increased power of the quantile unit root tests, they fail to find support for the PPP hypothesis in any quantile in seven of the twelve countries with only minor support in the extreme lower quantiles for the remaining countries. The latter suggests that positive shocks are always permanent in oil-exporting countries. In the absence of extreme negative shocks there is no evidence of mean reverting behaviour. The lack of support found in these tests is consistent with the findings of Mehrara (2007) who analyses thirteen oil-exporting countries, seven of which are the focus of this study.

However, relaxing the PPP specification, and adopting a cointegration approach, this paper finds support of nonlinear cointegration between the exchange rate and national prices across the whole distribution in seven of the twelve countries, and in the upper quantiles for a further three countries. This suggests there is a long-run equilibrium relationship between exchange rates and price levels in oil-exporting countries, but the standard PPP condition misspecifies this relationship for these countries. The characteristics of these countries explain why PPP is unrealistic. Many of these oil-exporting countries, with the exception of Canada, Mexico, and Russia, have highly concentrated and undiversified natural resource base with a limited stabilising mechanism to dampen the effects of the shocks. The volatility of global oil prices will drastically effect GDP and government spending in these countries and this effect will filter through to the exchange rate. These results call into question the validity of exchange rate theory in oil-exporting countries, and suggest there are opportunities for international arbitrage in the goods market. 


\section{References}

Agenor, Pierre-Richard, Christopher McDermott, and Eswar Prasad (2000). "Macroeconomic Fluctuations in Developing Countries: Some Stylized Facts." In: World Bank Economic Review 14.2, pp. 251-285.

Alba, Joseph D. and David H. Papell (2007). "Purchasing power parity and country characteristics: Evidence from panel data tests." In: Journal of Development Economics 83.1, pp. 240-251.

Alba, Joseph D. and Donghyun Park (2003). "Purchasing Power Parity in Developing Countries: Multi-Period Evidence Under the Current Float." In: World Development 31.12, pp. 2049-2060.

Amano, Robert A. and Simon Van Norden (1998). "Exchange Rates and Oil Prices." In: Review of International Economics 6.4, pp. 683-694. ISSN: 1467-9396.

Backus, David K. and J. Crucini (2000). "Oil prices and the terms of trade." In: Journal of International Economics 50.1, pp. 185-213.

Bahmani-Oskooee, Mohsen, Tsangyao Chang, Tsung-Hsien Chen, et al. (2017). "Revisiting purchasing power parity in Eastern European countries: quantile unit root tests." In: Empirical Economics 52.2, pp. 463-483.

Bahmani-Oskooee, Mohsen, Tsangyao Chang, Shu-Ching Cheng, et al. (2015). "Revisiting purchasing power parity in major oil-exporting countries." In: Macroeconomics and Finance in Emerging Market Economies 8.1-2, pp. 108-116.

Bahmani-Oskooee, Mohsen, Ilir Miteza, and A. B. M. Nasir (2002). "The long-run relation between black market and official exchange rates: evidence from panel cointegration." In: Economics Letters 76.3, pp. 397-404.

Bahmani-Oskooee, Mohsen and Omid Ranjbar (2016). "Quantile unit root test and PPP: evidence from 23 OECD countries." In: Applied Economics 48.31, pp. 2899 2911.

Chang, Tsangyao and Wen-Chi Liu (2010). "Long-run purchasing power parity with asymmetric adjustment: evidence from nine major oil-exporting countries." In: International Journal of Finance and Economics 15.3, pp. 263-274.

Chang, Tsangyao, Yang-Cheng Lu, Wen-Chi Liu, et al. (2010). "Revisiting purchasing power parity for major oil-exporting countries using panel SURADF tests." In: Applied Economics Letters 18.1, pp. 63-67.

Chang, Tsangyao, Yang-Cheng Lu, D. P. Tang, et al. (2011). "Long-run purchasing power parity with asymmetric adjustment: further evidence from African countries." In: Applied Economics 43.2, pp. 231-242.

Cheung, Yin-Wong and Kon S. Lai (2000). "On Cross-country differences in the persistence of real exchange rates." In: Journal of International Economics 50.2, pp. 375397. 
Coudert, Virginie, Valerie Mignon, and Alexis Penot (2008). "Oil Price and the Dollar." In: URL: https://EconPapers.repec.org/RePEc: hal : journl: halshs-00353404. Dehn, Jan (2000). The Effects on Growth of Commodity Price Uncertainty and Shocks. The World Bank.

Dutta, Jayasri and Hyginus Leon (2002). "Dread of Depreciations: Measuring Real Exchange Rate Interventions." In: IMF Working Paper, pp. 1913-1921.

Hosseinkouchack, Mehdi and Maik H. Wolters (2013). "Do large recessions reduce output permanently?" In: Economics Letters 121.3, pp. 516-519.

Koenker, Roger and Zhijie Xiao (2004). "Unit Root Quantile Autoregression Inference." In: Journal of the American Statistical Association 99.467, pp. 775-787.

- (2006). "Quantile Autoregression." In: Journal of the American Statistical Association 101.475, pp. 980-990.

MacDonald, R. and P. D. Murphy (1989). "Testing for the long run relationship between nominal interest rates and inflation using cointegration techniques." In: Applied Economics 21.4, pp. 439-447.

Mehrara, Mohsen (2007). "Testing the purchasing power parity in oil-exporting countries." In: OPEC Review 31.4, pp. 249-260.

Mendoza, Enrique (1995). "The Terms of Trade, the Real Exchange Rate, and Economic Fluctuations." In: International Economic Review 36.1, pp. 101-37.

Nikolaou, Kleopatra (2008). "The behaviour of the real exchange rate: Evidence from regression quantiles." In: Journal of Banking and Finance 32.5, pp. 664-679.

Sarno, Lucio (2000). "Real exchange rate behavior in the Middle East: a re-examination." In: Economics Letters 66.2, pp. 127-136.

Serletis, Apostolos and Periklis Gogas (2000). "Purchasing power parity, nonlinearity and chaos." In: Applied Financial Economics 10.6, pp. 615-622.

Taylor, Mark P. (1988). "An empirical examination of long-run purchasing power parity using cointegration techniques." In: Applied Economics 20.10, pp. 1369-1381.

Taylor, Mark P., David A. Peel, and Lucio Sarno (2001). "Nonlinear Mean-Reversion in Real Exchange Rates: Toward a Solution to the Purchasing Power Parity Puzzles." In: International Economic Review 42.4, pp. 1015-1042.

World Bank (2016). Fuel exports as a percentage of mechandise exports. URL: http: //data. worldbank.org/indicator/TX.VAL. FUEL. ZS. UN.

Xiao, Zhijie (2009). "Quantile cointegrating regression." In: Journal of Econometrics 150.2, pp. 248-260. 
Table 1: Summary Statistics

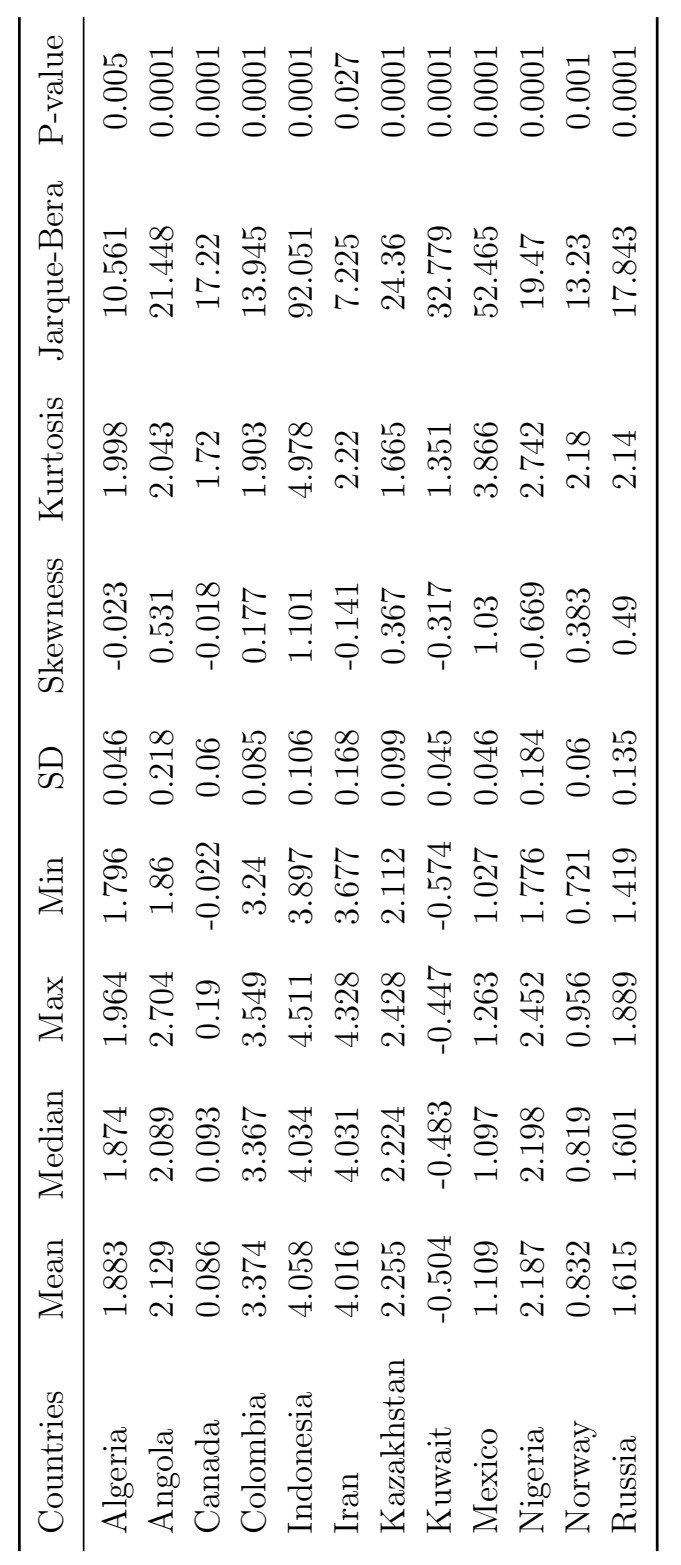


Table 2: Univariate Unit Root Tests

\begin{tabular}{lllllll}
\hline \hline & Level & \multicolumn{5}{l}{ 1st Difference } \\
\hline & ADF & PP & KPSS & ADF & PP & KPSS \\
\hline Algeria & $-1.631(0)$ & $-1.754[3]$ & $\mathbf{0 . 2 7 6 ( 1 2 )}$ & $-14.588(0)^{* * *}$ & $-14.588[0]^{* * *}$ & $0.113(2)$ \\
Angola & $-1.489(0)$ & $-1.785[4]$ & $1.749(12)^{* * *}$ & $-8.422(5)^{* * *}$ & $-14.618[1]^{* * *}$ & $0.105(4)$ \\
Canada & $-1.362(0)$ & $-1.343[6]$ & $1.073(12)^{* * *}$ & $-17.478(0)^{* * *}$ & $-17.409[6]^{* * *}$ & $0.191(6)$ \\
Colombia & $-1.440(0)$ & $-1.440[6]$ & $0.604(12)^{* *}$ & $-14.020(0)^{* * *}$ & $-1.969[4]^{* * *}$ & $0.121(1)^{* *}$ \\
Indonesia & $\mathbf{- 2 . 7 6 0 ( 0 ) *}$ & $\mathbf{- 2 . 6 5 5}[\mathbf{4}]^{*}$ & $0.728(11)^{* * *}$ & $-12.780(1)^{* * *}$ & $-14.857[9]^{* * *}$ & $0.094(8)$ \\
Iran & $-2.214(0)$ & $-2.214[0]$ & $\mathbf{0 . 3 3 1 ( 1 2 )}$ & $-16.291(0)^{* * *}$ & $-16.300[3]^{* * *}$ & $0.055(4)$ \\
Kazakhstan & $-1.389(1)$ & $-1.631[7]$ & $0.653(12)^{* *}$ & $-11.581(0)^{* * *}$ & $-11.533[4]^{* * *}$ & $0.172(7)$ \\
Kuwait & $-0.130(0)$ & $-0.170[2]$ & $1.666(12)^{* * *}$ & $-15.606(0)^{* * *}$ & $-15.616[2]^{* * *}$ & $0.302(2)$ \\
Mexico & $-1.523(0)$ & $-1.547[2]$ & $0.360(11)^{*}$ & $-15.166(0)^{* * *}$ & $-15.153[2]^{* * *}$ & $0.476^{* *}$ \\
Nigeria & $-2.066(0)$ & $-2.115[3]$ & $\mathbf{0 . 2 7 8}(\mathbf{1 2})$ & $-15.516(0)^{* * *}$ & $-15.517[2]^{* * *}$ & $0.140(2)$ \\
Norway & $-1.549(0)$ & $-1.572[2]$ & $0.420(12)^{*}$ & $-16.392(0)^{* * *}$ & $-16.392[0]^{* * *}$ & $0.147(1)$ \\
Russia & $-1.491(1)$ & $-1.332[2]$ & $1.003(12)^{* * *}$ & $-11.762(0)^{* * *}$ & $-11.657[6]^{* * *}$ & $0.163(1)$ \\
\hline
\end{tabular}

Bold values represent support for the PPP hypthesis. *** denotes $1 \%$ confidence level, ${ }^{* *}$ denotes $5 \%$ confidence level, and ${ }^{*}$ denotes $10 \%$ confidence level. The number in brackets represents the truncation for the Barlett Kernel, as suggested by the Newey-West test. The number in square brackets represents the lag order selected based on the recursive t-statistic. 
Table 3: Quantile Unit Root Tests

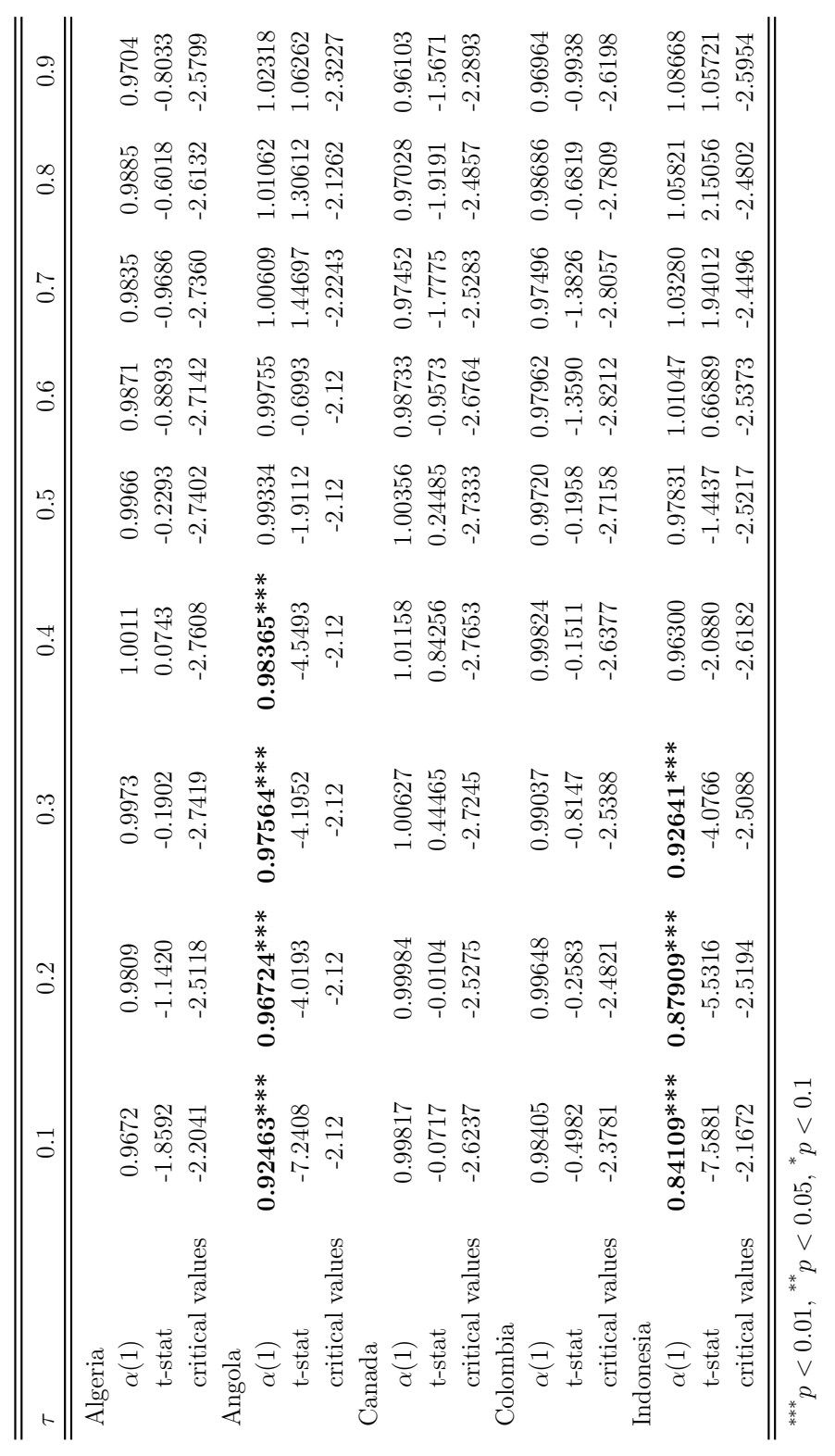


Table 4: Quantile Unit Root Tests: Part Two

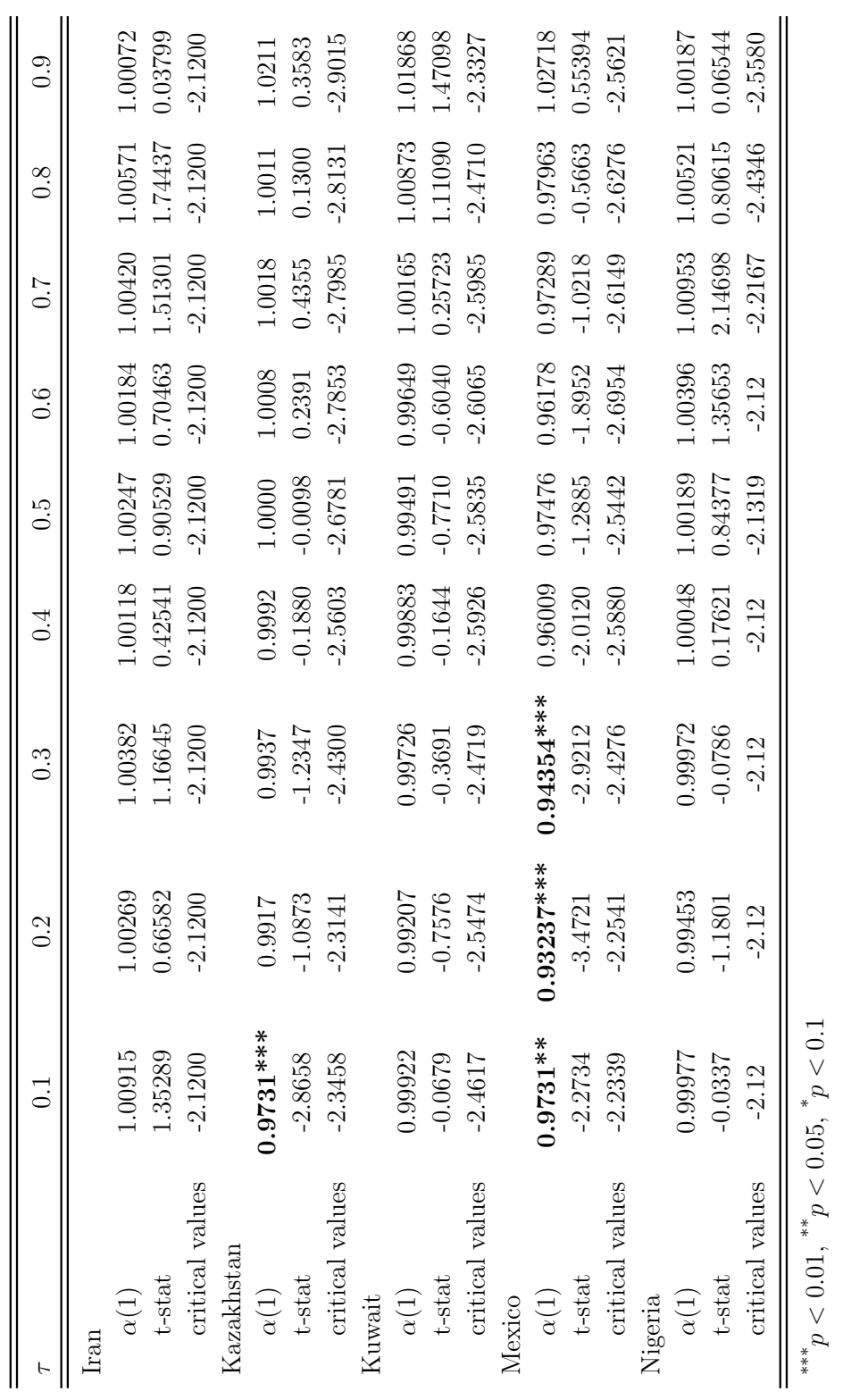


Table 5: Quantile Unit Root Tests: Part Three




Table 6: Quantile Estimation Results

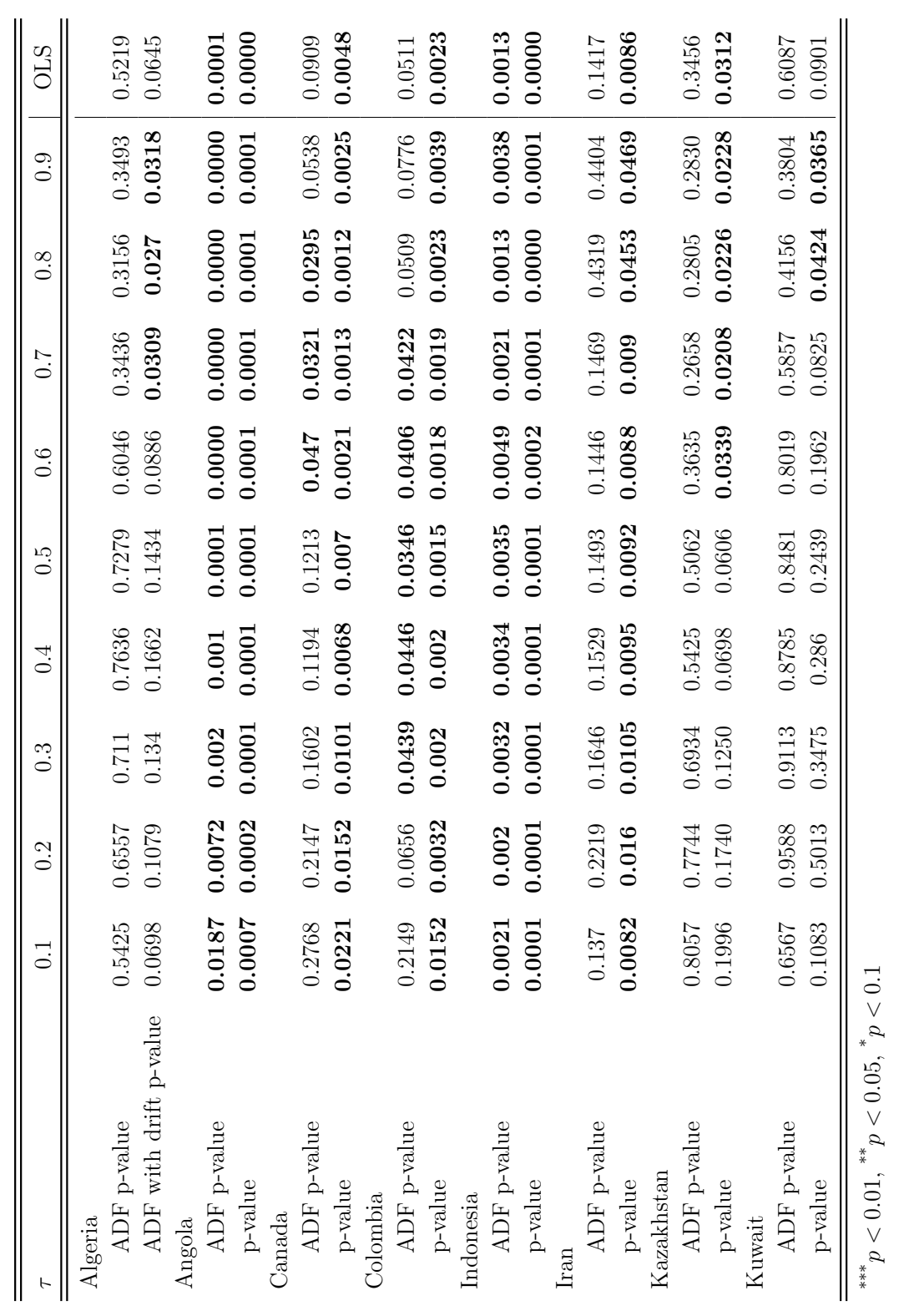


Table 7: Quantile Estimation Results Cont.

\begin{tabular}{|c|c|c|c|c|}
\hline$\underline{0}$ & 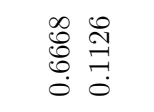 & 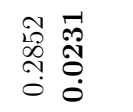 & 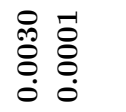 &  \\
\hline$\stackrel{8}{0}$ & 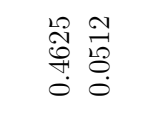 & 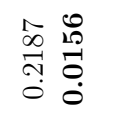 & $\begin{array}{ll}8 & 0 \\
8 & 8 \\
0 & 8 \\
0 & 0\end{array}$ & 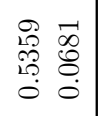 \\
\hline $\begin{array}{l}\infty \\
0 \\
0\end{array}$ & $\begin{array}{ll}\vec{\delta} & \mathscr{0} \\
\stackrel{0}{\circ} & 0 \\
0 & 0 \\
0 & 0\end{array}$ & 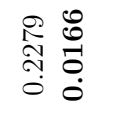 & $\begin{array}{ll}8 & -1 \\
8 & 8 \\
0 & 0 \\
0 & 0 \\
0\end{array}$ & 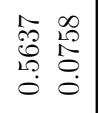 \\
\hline$\stackrel{5}{0}$ & 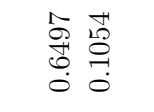 & 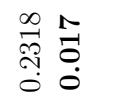 & $\begin{array}{l}8 \\
\stackrel{8}{8} \\
\stackrel{8}{8} \\
\dot{0} \\
\dot{0}\end{array}$ & 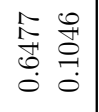 \\
\hline $\begin{array}{l}\dot{0} \\
\dot{0}\end{array}$ &  & 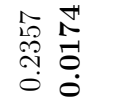 & 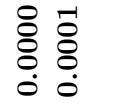 & \begin{tabular}{ll}
0 & 0 \\
\multirow{H}{*}{} & $\stackrel{1}{0}$ \\
0 & -1 \\
0 & 0
\end{tabular} \\
\hline 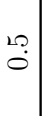 & $\begin{array}{l}\overrightarrow{\mathscr{\theta}} \\
\stackrel{0}{\infty} \\
\stackrel{0}{0}\end{array}$ & 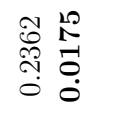 & $\begin{array}{ll}-1 & -1 \\
8 & 8 \\
8 & 8 \\
0 & 0 \\
0\end{array}$ & 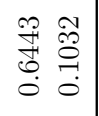 \\
\hline$\stackrel{\square}{\longrightarrow}$ & 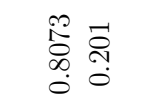 & $\begin{array}{ll}\overrightarrow{\mathscr{N}} & \stackrel{\theta}{0} \\
\stackrel{-}{0} & \stackrel{0}{0} \\
0 & 0\end{array}$ & $\begin{array}{ll}-\overrightarrow{8} \\
\stackrel{8}{8} \\
\dot{0} \\
\dot{0}\end{array}$ &  \\
\hline  & 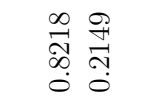 &  & $\begin{array}{l}\text { ô } \\
\dot{\delta} \\
\dot{8} \\
\dot{0} \\
\dot{0}\end{array}$ & 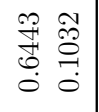 \\
\hline ֶֶ & 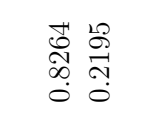 & 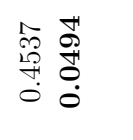 & 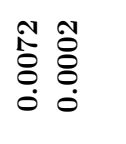 & $\begin{array}{cc}\overrightarrow{0} & \stackrel{20}{9} \\
0 & \stackrel{0}{0} \\
0 & 0\end{array}$ \\
\hline &  & $\begin{array}{ll}\stackrel{9}{9} & \stackrel{9}{+1} \\
\stackrel{3}{9} & 0 \\
& 0\end{array}$ & $\begin{array}{l}r \\
\infty \\
\infty \\
0 \\
0 \\
0 \\
0 \\
0 \\
0\end{array}$ &  \\
\hline &  & 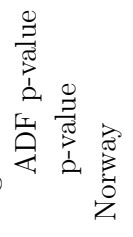 & 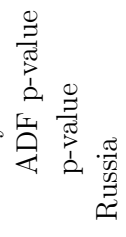 & 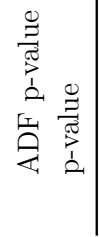 \\
\hline
\end{tabular}



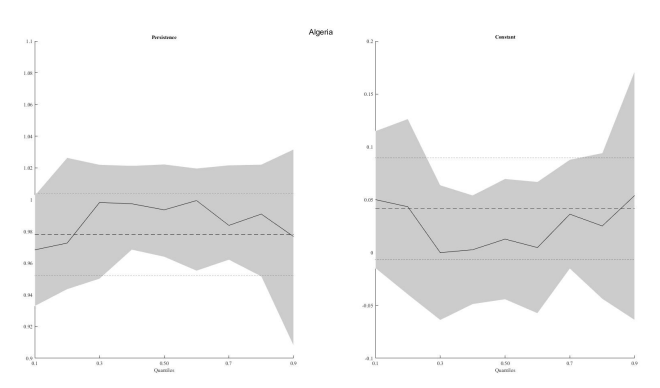

(a) QAR Estimation for Algeria
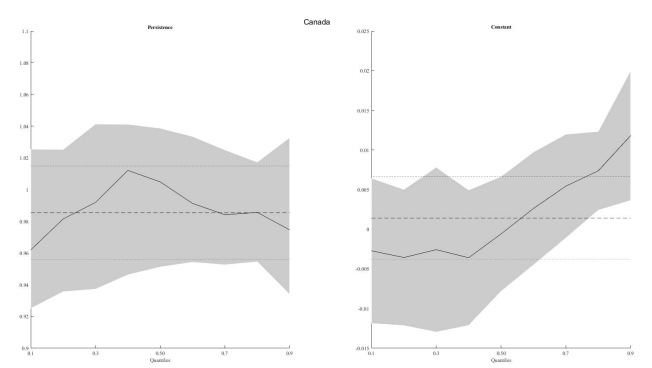

(c) QAR Estimation for Canada
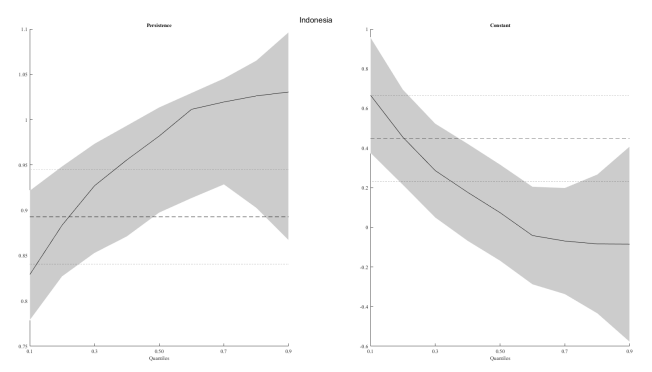

(e) QAR Estimation for Indonesia

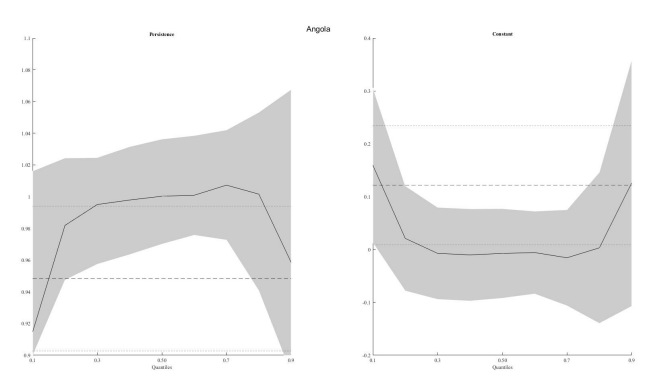

(b) QAR Estimation for Angola

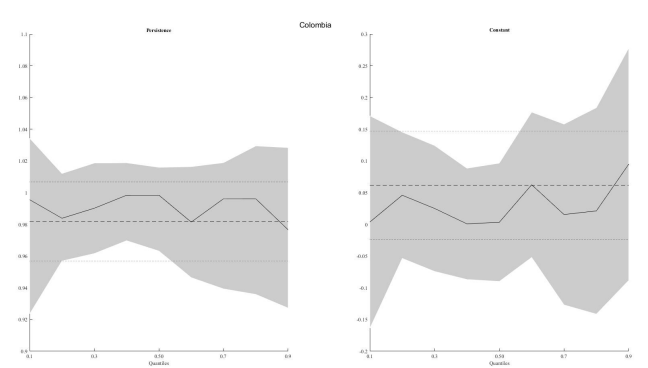

(d) QAR Estimation for Colombia
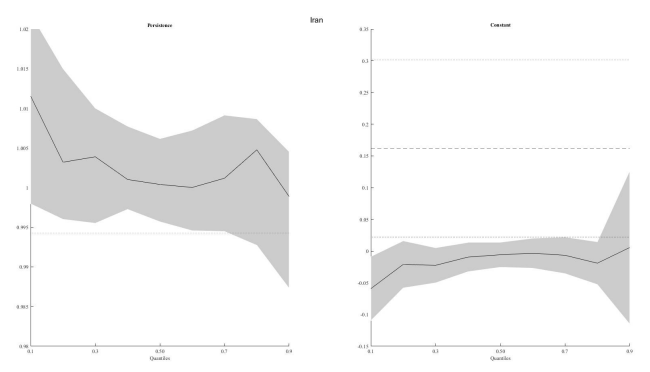

(f) QAR Estimation for Iran

Figure 1: Quantile Unit Root Tests - The left hand side of each figure reports the estimation of the persistence parameter: $\alpha(\tau)$. The right hand side of each figure reports the constant parameter: $a(\tau)$. The grey shaded area represents the $95 \%$ confidence bands. 

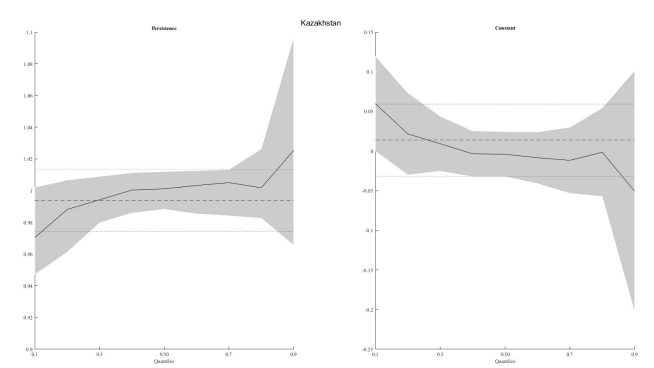

(g) QAR Estimation for Kazakhstan
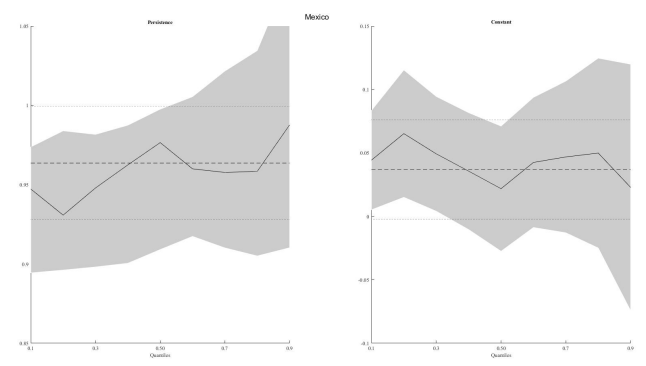

(i) QAR Estimation for Mexico
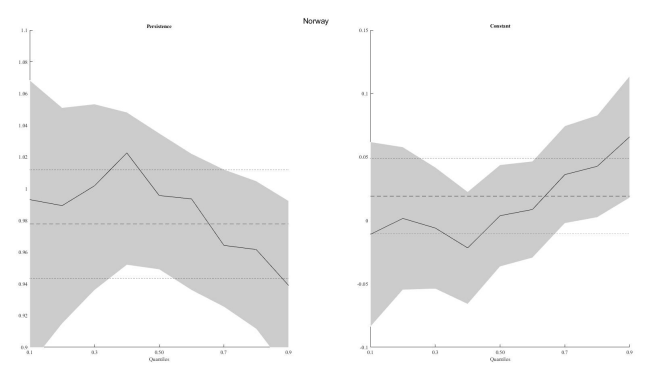

(k) QAR Estimation for Norway

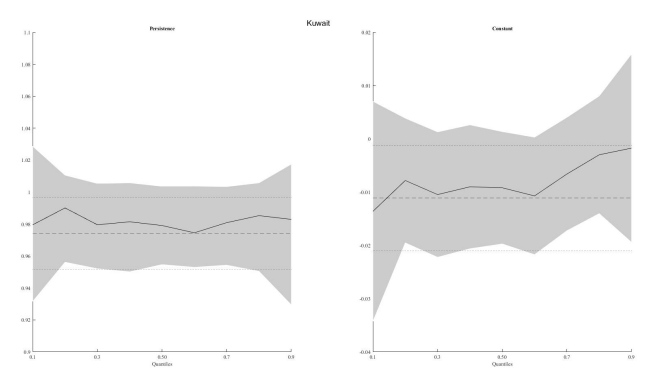

(h) QAR Estimation for Kuwait

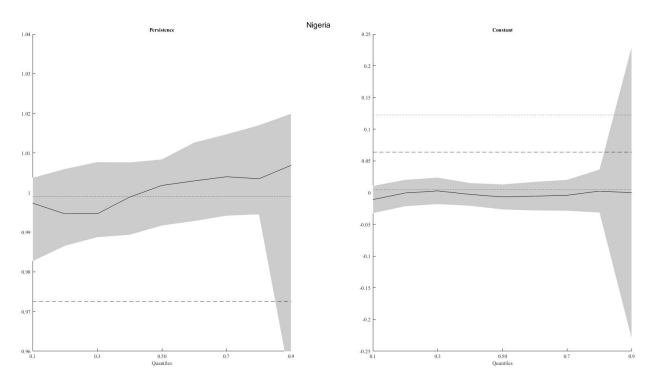

(j) QAR Estimation for Nigeria

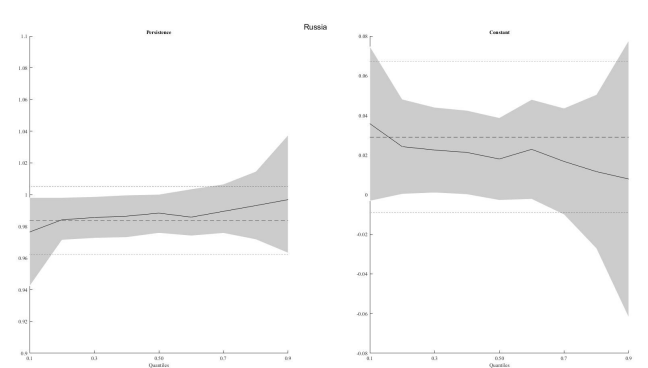

(1) QAR Estimation for Russia

Figure 1: Quantile Unit Root Tests Cont. - The left hand side of each figure reports the estimation of the persistence parameter: $\alpha(\tau)$. The right hand side of each figure reports the constant parameter: $a(\tau)$. The grey shaded area represents the $95 \%$ confidence bands. 

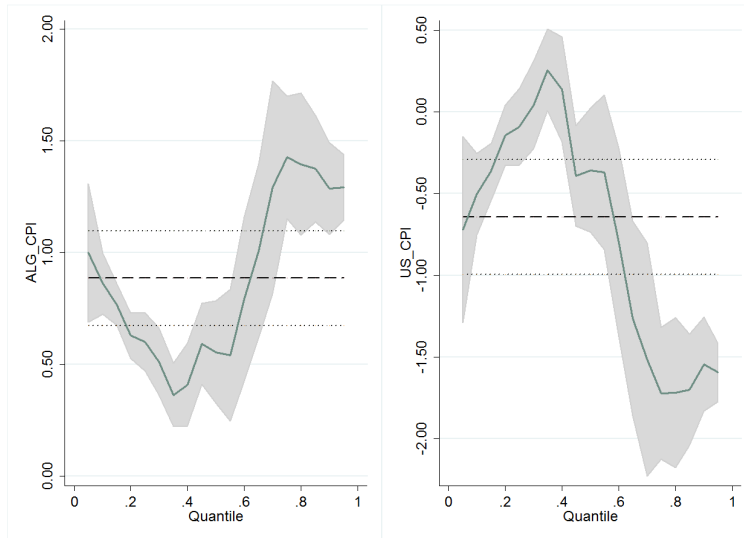

(a) Flexible Quantile Estimation for Algeria
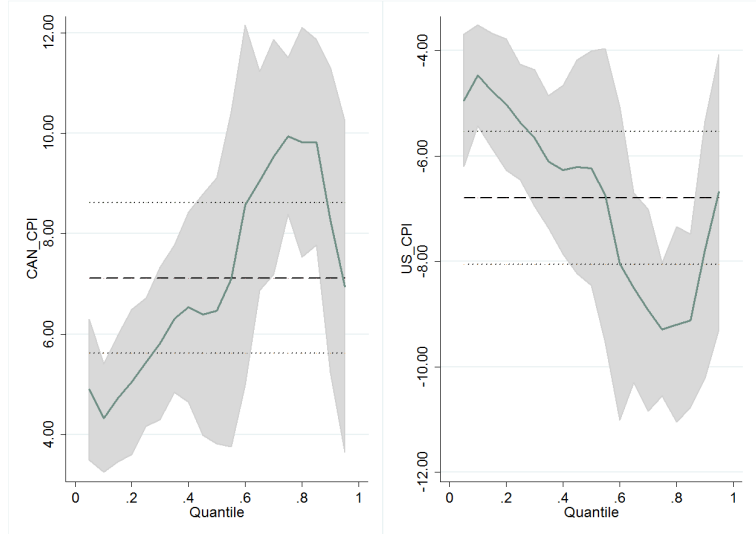

(c) Flexible Quantile Estimation for Canada
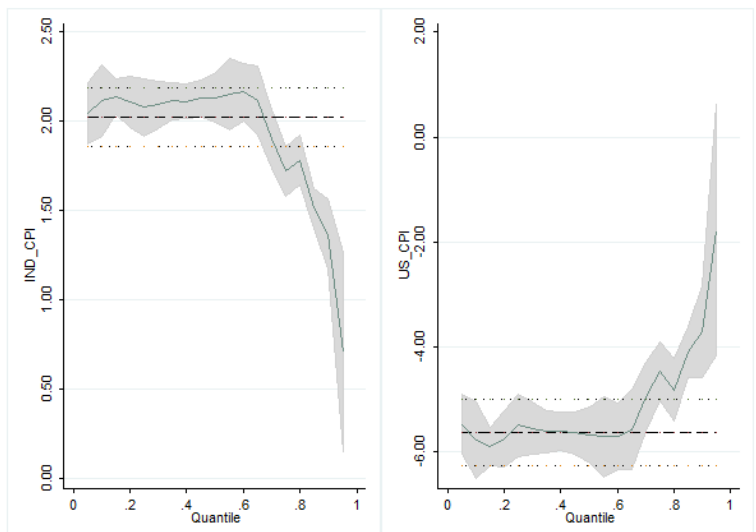

(e) Flexible Quantile Estimation for Indonesia
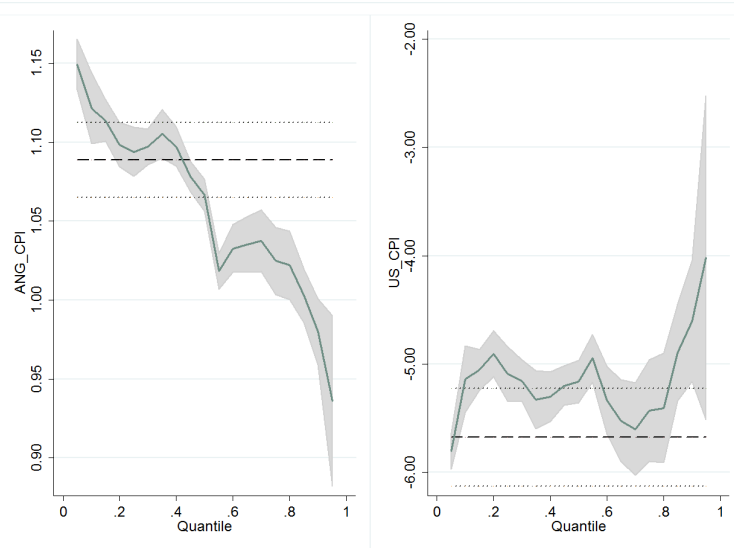

(b) Flexible Quantile Estimation for Angola
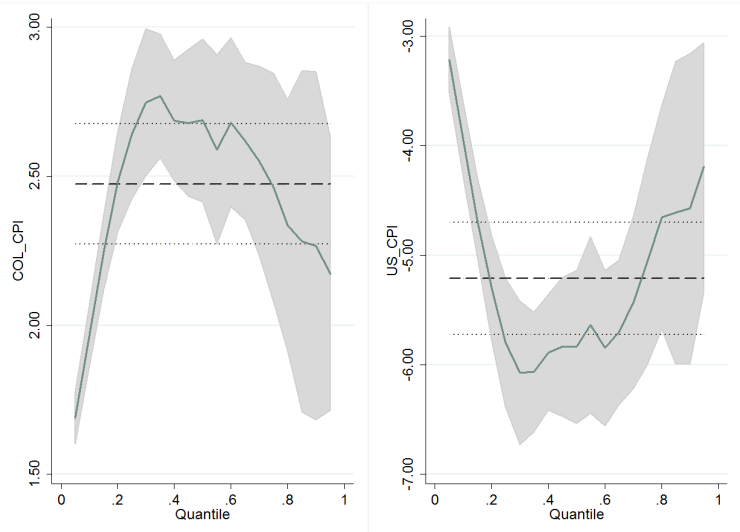

(d) Flexible Quantile Estimation for Colombia
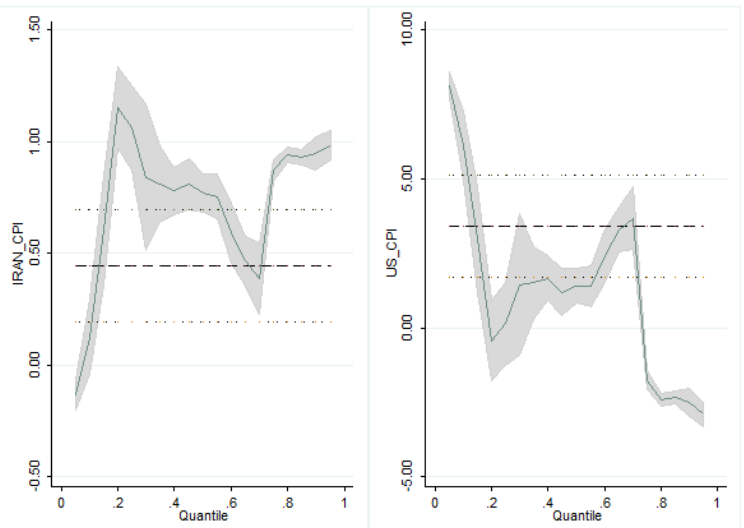

(f) Flexible Quantile Estimation for Iran

Figure 2: Flexible Quantile Estimation - The left hand side of each figure reports the estimation of the $\beta(\tau)$. The right hand side of each figure reports the estimation of the $\beta_{f}(\tau)$. The grey shaded area represents the $95 \%$ confidence bands. For comparison, the black dotted lines, and grey dotted lines, represent the OLS estimates and 95\% confidence bands, respectively. 

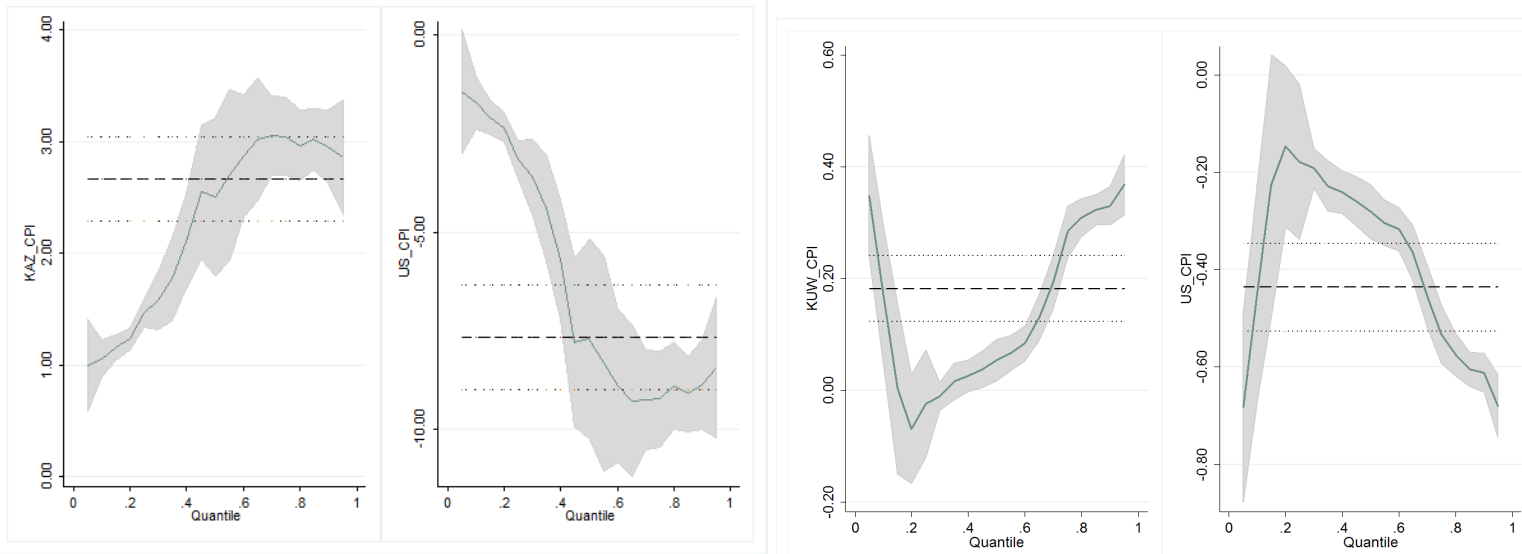

(g) Flexible Quantile Estimation for Kazakhstan
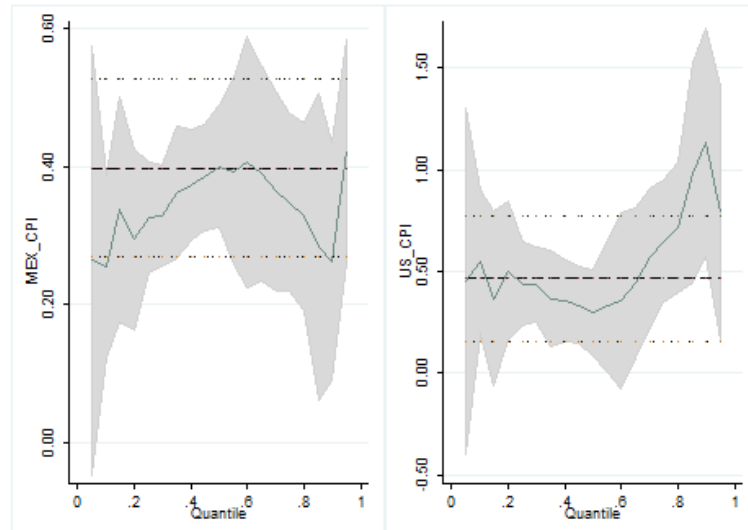

(h) Flexible Quantile Estimation for Kuwait

(i) Flexible Quantile Estimation for Mexico
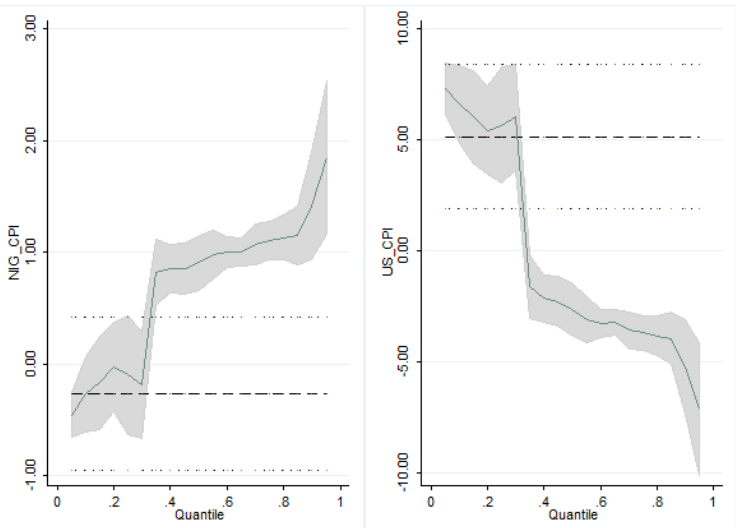

(j) Flexible Quantile Estimation for Nigeria
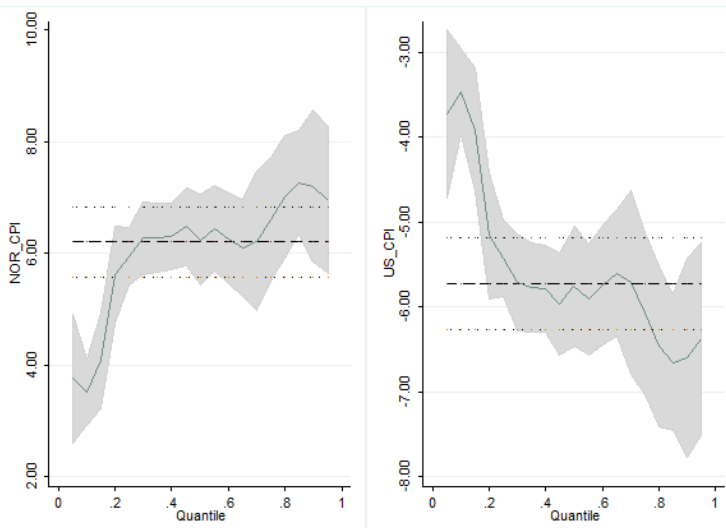

(k) QAR Estimation for Norway
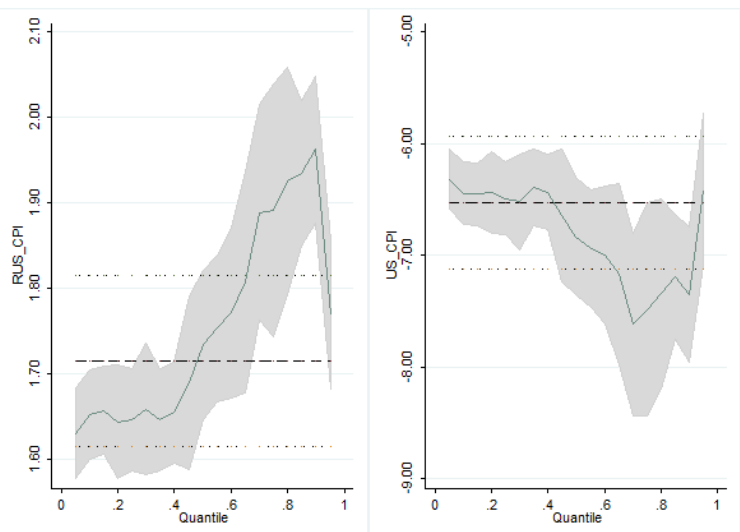

(1) QAR Estimation for Russia

Figure 2: Flexible Quantile Estimation Cont. - The left hand side of each figure reports the estimation of the $\beta(\tau)$. The right hand side of each figure reports the estimation of the $\beta_{f}(\tau)$. The grey shaded area represents the $95 \%$ confidence bands. For comparison, the black dotted lines, and grey dotted lines, represent the OLS estimates and 95\% confidence bands, respectively. 